\title{
Generation of a Mutant Population for TILLING Common Bean Genotype BAT 93
}

\author{
Timothy G. Porch ${ }^{1}$ \\ USDA-ARS, Tropical Agriculture Research Station, 2200 P.A. Campos Avenue, Suite 201, Mayaguez, \\ 00680, Puerto Rico \\ Matthew W. Blair \\ Centro Internacional de Agricultura Tropical (CIAT), A.A. 6713, Cali, Colombia \\ Patricia Lariguet \\ Laboratory of Molecular Biology of Higher Plants (LBMPS), University of Geneva, 30 quai \\ Ernest-Ansermet, 1211 Geneva, Switzerland \\ Carlos Galeano \\ CIAT, A.A. 6713, Cali, Colombia \\ Clive E. Pankhurst and William J. Broughton \\ LBMPS, University of Geneva, 30 quai Ernest-Ansermet, 1211 Geneva, Switzerland
}

\begin{abstract}
Additional INDEX words. EMS, mutagenesis, Phaseolus vulgaris
ABstract. Common bean (Phaseolus vulgaris) is the major food legume worldwide, making it an important target for novel approaches of genetic analysis. This study evaluated the use of ethyl methane sulfonate (EMS) for the generation of a mutant population for targeted induced local lesions in genomes (TILLING) in common bean. TILLING is a powerful reverse genetics approach that uses a large mutant population for identification of mutants in loci of interest. Based on overall survival, development, and yield of treated seed, 40 mм EMS was found to be an appropriate concentration for the generation of a mutant population in common bean genotype BAT 93. Higher concentrations of EMS resulted in survival rates of less than $10 \%$ and lower concentrations resulted in the generation of fewer mutants. Based on TILLING results from other species, a population of 5000 lines is estimated to be sufficient for saturation of the common bean genome. Phenotypic mutation frequencies and the isolation of targeted mutations in the BAT 93 mutant population indicate that mutagenesis was effective.
\end{abstract}

Common bean is the principal grain legume used for direct human consumption worldwide (Broughton et al., 2003) and is increasingly recognized for its high nutritional quality. Thus, it is an important target for intensive genomics research such as reverse genetic approaches like targeted induced local lesions in genomes (TILLING). Common bean is a true diploid with 11 chromosomes and a haploid complement of 588 (Bennett and Leitch, 2005) to $637 \mathrm{Mbp}$ (Arumuganathan and Earle, 1991). Its small genome, with a low incidence of duplications, makes it suitable for sequencing and genomic applications and as a reference for the elucidation of genomes of more complex legume species such as soybean (Gepts et al., 2005). Phaseolus vulgaris is closely related to other cultivated Phaseolus species, including $P$. acutifolius (tepary bean), $P$. coccineus (scarlet runner bean), and $P$. lunatus (lima bean) as well as to legumes in the Phaseoleae tribe, including Cajanus cajan (pigeonpea),

Received for publication 22 May 2008. Accepted for publication 25 Mar. 2009 The work conducted at the University of Geneva was supported by the Fonds National Suisse de la Recherche Scientifique (Projects 3100AO-104097 and 3100A0-116858) as well as the Département de l'Instruction Publique du Canton de Genève.

We thank Y.Y. Aung, A. Hincapie, A. Montes, and A. Quiles for their contributions to the development of the mutant population.

Mention of trade names or commercial products in this article is solely for the purpose of providing specific information and does not imply recommendation or endorsement by the U.S. Department of Agriculture.

${ }^{1}$ Corresponding author. E-mail: timothy.porch@ars.usda.gov.
Glycine max (soybean), Vigna radiata (mungbean), and Vigna unguiculata (cowpea) (Broughton et al., 2003). Common bean has a well-developed genetic map (Freyre et al., 1998), markers linked to agronomically important traits (Kelly et al., 2003), active development of expressed sequence tag resources (Melotto et al., 2005; Ramírez et al., 2005), and several bacterial artificial chromosome (BAC) libraries (Kami et al., 2006; Vanhouten and MacKenzie, 1999). Although forward genetic tools are rapidly being developed, reverse genetic approaches have been unavailable in common bean as a result of the absence of an effective transformation protocol and thus the inability to develop transposon-based or T DNA-based mutagenesis systems. TILLING has been shown to be effective in legumes such as soybean (Cooper et al., 2008), Lotus japonicus (Perry et al., 2003), and Medicago trucatula (Javot et al., 2007). The establishment of mutation protocols and mutant populations in common bean is thus important.

Radioisotopes, $\mathrm{x}$-ray, and chemical mutagens have been used previously to induce mutations in common bean. Gamma radiation has been used for the breeding of seed yield and quality (Sarafi, 1973), seed color (Allavena, 1989; Hussein and Disouki, 1976; Wyatt and Dukes, 1980), insect resistance (Mohan et al., 1980), and disease resistance (Allavena, 1989; Tulmann-Neto and Ando, 1976; Zogorcheva and Poriazov, 1983). Gamma radiation has also been used for the study of specific morphological mutations (Frazier and Davis, 1966a, 1966b; Nagata and Bassett, 1984). X-rays were used to modify 
growth habit, resulting in the development of the determinate navy bean cultivar, Sanilac (Andersen and Down, 1956). Several chemical mutagens have also been used, including azide (Cary, 1982), N-ethylnitrosourea (Svetleva, 2004), and ethyl methane sulfonate (Motto et al., 1975). Ethyl methane sulfonate (EMS) has been used to generate mutations in seedcoat color (Moh, 1971), biological nitrogen fixation (Davis et al., 1988; Gautam et al., 1998; Pankhurst et al., 2004; Park and Buttery, 1989), phytic acid biosynthesis (Sparvoli et al., 2007), and seed development (Silue et al., 2006).

EMS is the most widely used mutagen in plants for the development of large mutant populations primarily because it creates large numbers of point mutations in almost all species studied, but also because the mutation frequency seems to be independent of genome size (Greene et al., 2003; Henikoff and Comai, 2003; McCallum et al., 2000). Thus, saturation of the genome with mutants can be achieved with relatively small populations. Nevertheless, attempts at TILLING in some species such as rice (Oryza sativa) have been confounded by low mutation frequencies and high rates of lethality at higher mutagen concentrations (Till et al., 2007). A balance must therefore be sought between efficient mutagenesis and plant lethality by selecting the highest mutation frequency that yields adequate plant survival. Mutation frequency can be estimated based on phenotypic traits such as albinism and embryo lethality; however, these phenotypic traits can sometimes be difficult to measure (Till et al., 2007; Wu et al., 2005). Previous mutagenesis in common bean using EMS has used concentrations ranging from 10 to $80 \mathrm{~mm}$ (Davis et al., 1988, Gautam et al., 1998). In another study, the concentration of EMS, the length of the treatment, and the ambient temperature were found to affect the efficiency of mutagenesis (Pankhurst et al., 2004). Additionally, different species and even different genotypes within the same species can react distinctly to mutagenesis (Till et al., 2007; Wu et al., 2005). Thus, as a result of the variable genotypic response to the mutagen, comprehensive testing of specific genotypes selected for mutagenesis population development is necessary.

Several considerations were evaluated for the selection of a genotype for mutagenesis. The ideal genotype should be broadly adapted; should be well-studied using molecular, genetic, and physiological methods; should harbor desirable traits for study; and should have high rates of multiplication and ease of agronomic management. To ensure that the mutants of interest are generated, mutations must theoretically be produced at every locus of the genome. Saturation of the $L$. japonicus genome $(470 \mathrm{Mb})$ was achieved through the development of 3800 independent M2 lines (Perry et al., 2003). Because common bean has a larger genome $(590 \mathrm{Mb})$, the appropriate population size to ensure saturation could be larger.

\section{Materials and Methods}

Plant material. Common bean genotype BAT 93, a representative of the Mesoamerican gene pool, was bred for high productivity in tropical conditions at the Centro Internacional de Agricultura Tropical (CIAT), Colombia (Voysest, 1983, 2000). It was selected from a double cross population developed between landraces. BAT 93 was selected for mutagenesis (Table 1) because it is one of the parents of the core common bean mapping population (Freyre et al., 1998), it has been used in the generation of a large BAC library (Kami et al., 2006), and it is amenable for production in temperate and tropical environments and under growth chamber, greenhouse, or field conditions (Blair et al., 2005). BAT 93 also possesses several desirable characteristics (Table 1), including disease resistance (Sanchez-Valdez et al., 2004). Seed of BAT 93 were carefully generated for the experiment from single plant selections and confirmed for homogeneity using simple sequence repeat marker analysis at CIAT.

Optimization OF EMS CONCENTRATION. Initial experiments on EMS concentrations were conducted as part of the development of a mutagenesis protocol for common bean at the University of Geneva, Geneva, Switzerland. In the first protocol, $40 \mathrm{~g}$ of BAT 93 seed ( $\approx 200$ seeds) were added to separate $500-\mathrm{mL}$ flasks and surface-sterilized with $70 \%(\mathrm{v} / \mathrm{v})$ ethanol for $10 \mathrm{~min}$ and $5 \%(\mathrm{v} / \mathrm{v}) \mathrm{H}_{2} \mathrm{O}_{2}$ for $10 \mathrm{~min}$. After rinsing the seed with sterile water, $180 \mathrm{~mL}$ of water containing EMS concentrations ranging from 0 to $80 \mathrm{~mm}$ was added to each flask. The flasks were then placed in an incubator shaker and shaken slowly $(78 \mathrm{rpm})$ at $20^{\circ} \mathrm{C}$ for $15 \mathrm{~h}$. The seed was then rinsed 20 times with sterile water before planting in trays of

Table 1. Considerations for selecting the common bean BAT 93 genotype for mutagenesis and targeted induced local lesions in genomes (TILLING).

\begin{tabular}{|c|c|c|}
\hline Consideration & Description & Reference \\
\hline \multicolumn{3}{|l|}{ Physiological characterization } \\
\hline General adaptation & Adapted to temperate and tropical environments & Blair et al., 2005 \\
\hline Plant and seed characteristics & $\begin{array}{l}\text { Type III prostrate plant habit, photoperiod } \\
\text { insensitive, small beige seeds }\end{array}$ & Sanchez-Valdez et al., 2004 \\
\hline Disease resistance & $\begin{array}{l}\text { Bean common mosaic virus ( } I \text { gene }) \text {, rust, } \\
\text { angular leaf spot, anthracnose, common } \\
\text { bacterial blight }\end{array}$ & $\begin{array}{l}\text { Kelly et al., } 2003 \text { (review of mapped } \\
\text { QTL); Sanchez-Valdez et al., } 2004\end{array}$ \\
\hline Genetic structure of genotype & Homozygous, homogeneous & Blair et al., 2005 \\
\hline Pedigree & $(\mathrm{G} 3709 \times \mathrm{G} 1320) \times(\mathrm{G} 3645 \times \mathrm{G} 5478)$ & M.W. Blair, personal communication \\
\hline BAC libraries & $\begin{array}{l}\text { Largest common bean bacterial artificial } \\
\text { chromosome (BAC) library, } 20 \times \text { coverage }\end{array}$ & $\begin{array}{l}\text { Kami et al., 2006; Vanhouten and } \\
\text { MacKenzie, } 1999\end{array}$ \\
\hline Ongoing EST sequencing efforts & $\begin{array}{l}\text { Expressed sequence tag (EST) sequenced from } \\
\text { various tissues }\end{array}$ & $\begin{array}{l}\text { Described in Broughton et al., 2003; } \\
\text { and in other genotypes (Melotto et al., 2005; } \\
\text { Ramirez et al., 2005) }\end{array}$ \\
\hline
\end{tabular}


sterile vermiculite (Pankhurst et al., 2004). A second protocol was tested at CIAT (Colombia) and was based on a method used with barley (Hordeum vulgare) (Caldwell et al., 2004), the principle difference being the addition of an 8-h imbibition step before EMS treatment. EMS concentrations of 0.0, 19.4, 48.5, 77.7 , and $106.0 \mathrm{~mm}$ (equivalent to $0 \%, 0.2 \%, 0.5 \%, 0.8 \%$, and $1.0 \% \mathrm{v} / \mathrm{v}$, respectively; Expt. 1) and 0.0, 19.4, 29.1, 38.8, and $48.5 \mathrm{~mm}$ (equivalent to $0 \%, 0.2 \%, 0.3 \%, 0.4 \%$, and $0.5 \% \mathrm{v} / \mathrm{v}$, respectively; Expt. 2) were tested using this protocol. All seeds were planted in sterilized soil mix and fertilized. Germination data were collected at 7 and $10 \mathrm{~d}$ after planting.

After these initial experiments, EMS concentrations were targeted to a narrower range and a larger replicated experiment was conducted at the U.S. Department of Agriculture (USDA), Agriculture Research Service (ARS), Tropical Agriculture Research Station (TARS) in Mayaguez, PR, from Feb. to Apr. 2007. Seeds of BAT 93 were treated with EMS in the laboratory using the first protocol described. Six EMS concentrations, including $0,20,30,40,50$, and $60 \mathrm{~mm}$, were evaluated. The treated seeds were then rinsed 20 times in water and planted in seedling trays in Sunshine Mix \#1 (Sun Gro Horticulture, Vancouver, BC, Canada) in a greenhouse. Each EMS treatment was composed of three replicates planted in a randomized complete block design with the experimental unit being a seedling tray containing 72 seeds. Germination data were collected 7 and $14 \mathrm{~d}$ after planting, and plant height data were collected on Day 14. For germination data, the control (0 mM EMS) treatment was adjusted to $100 \%$ germination and the other treatments adjusted accordingly. Ten randomly selected surviving seedlings from each replicate were transplanted to $15-\mathrm{cm}$ diameter round pots in Sunshine Mix \#1, watered regularly to avoid drought stress, treated with pesticides as needed, and fertilized with Osmocote (14N-6.1P-11.6K; Scotts, Marysville, $\mathrm{OH})$. Seed yield component data were collected at harvest. The experiment was repeated twice. A combined data analysis using both experiments was completed after the homogeneity of error variances was tested. Least significant difference (LSD, $\alpha=0.05$ ) was used to compare the mean of each trait by EMS concentration treatment using SAS (SAS Institute, Cary, NC).

Mutant population Development. After mutagenesis of BAT 93 at the University of Geneva (Switzerland), USDAARS-TARS (Puerto Rico), and CIAT (Colombia), population development (Fig. 1) was initiated based on protocols developed for Arabidopsis thaliana (Colbert et al., 2001; McCallum et al., 2000). Between 2006 and 2008, cycles of
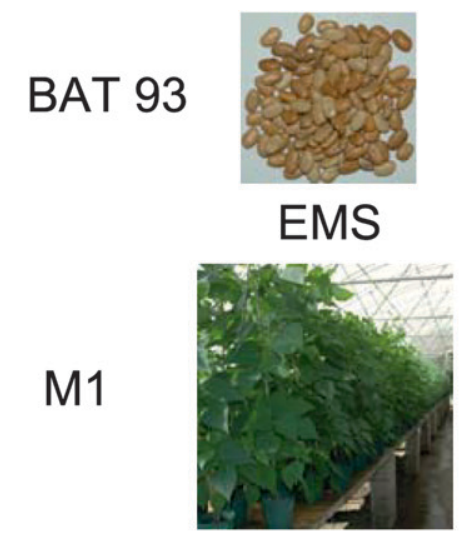

$\otimes$

M2

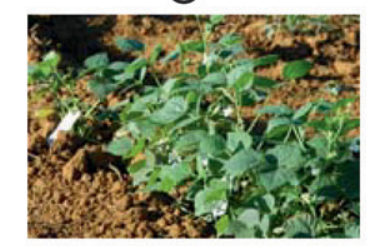

$\otimes$

M3

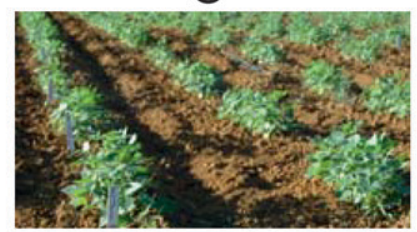

$\otimes$

M4

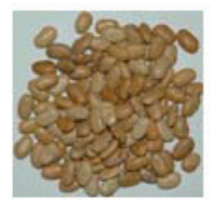

Wild type seed

EMS treatment

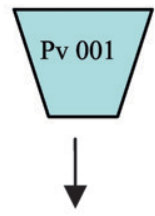

8 M2 seed sown of each M1 line

$8 \mathrm{M} 2 \mathrm{~s}$, from each M1, planted in field;

DNA Extracted

20 M3s, from each M2, planted in field

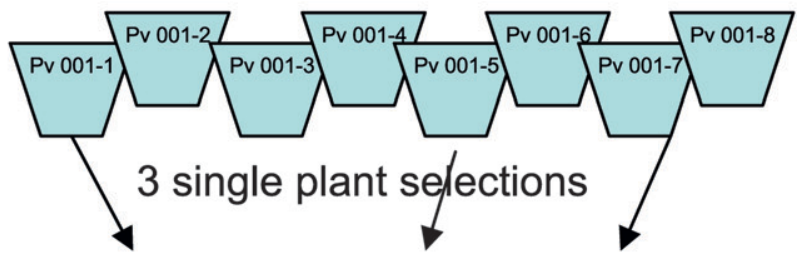

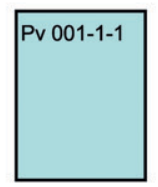
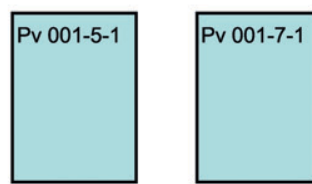

Each plot of 20 plants bulked

Seed stored

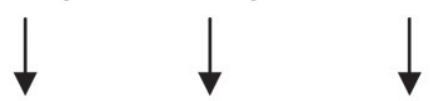

Testing/Distribution of mutants

Fig. 1. Protocol developed for the generation of a large mutant population for targeted induced local lesions in genomes (TILLING) in common bean genotype BAT 93 using ethyl methane sulfonate (EMS) seed treatment. Each generation after mutagen treatment is indicated by the letter M followed by the generation number. 
mutagenesis were initiated followed by generation advance of manageable subsets of the population. EMS concentrations of $35,40,45$, and 50 $\mathrm{mm}$ were used for the development of the mutagen population. The M1 generation was planted in the greenhouse in Puerto Rico and Colombia and harvested individually at maturity. Eight M2 seeds of each M1 line were planted in the field in Colombia and Puerto Rico during the dry winter season. Leaf material from three to four randomly selected M2 plants was collected and DNA extracted and seed from those same M2 plants was harvested individually. Twenty M3 seeds of each selected M2 line were planted in the field in Puerto Rico and Colombia and M4 seed was bulk-harvested from each line for storage. M4 mutant seed was stored and will be used for conducting both forward (systematic phenotypic screening) and reverse genetic analysis, and M2 DNA will be used for reverse genetic analysis.

Phenotypic evaluation of mutant population. A total of 3000 M2 plants were evaluated for aboveground phenotypic mutations. This population of $3000 \mathrm{M} 2$ plants was generated from 750 independent M1 plants with four M2 plants advanced from each M1 individual. Of the 3000 M2 plants, 844 were generated from a $35 \mathrm{~mm}$ EMS treatment and 2156 were generated from EMS concentrations between 40 and $50 \mathrm{~mm}$. If present, mutations were identified in one or more of the M2 plants in the plot of eight plants. The mutations were organized and classified based on mutated tissue, including leaf, stem, seed, and whole plant traits. The percent occurrence of the mutation in the M2 population was then calculated.

For the root nodulation tests, seed from 348 M2 lines, derived from EMS concentrations between 40 and $50 \mathrm{~mm}$, were evaluated. Seeds were surface-sterilized with concentrated $\mathrm{H}_{2} \mathrm{SO}_{4}$ for $10 \mathrm{~min}$ followed by six washes with sterile water and allowed to germinate on $\mathrm{B}+\mathrm{D}$ agar (Broughton and Dilworth, 1971). Germinated seed were then planted in pots containing sterile vermiculite, watered with the nitrogen-free $\mathrm{B}+\mathrm{D}$ solution, and inoculated with Rhizobium etli strain 1597 before planting. The $R$. etli was grown using standard protocols (Pueppke and Broughton, 1999) and diluted in B+D solution to a final concentration of $10^{7}$ bacteria/mL for inoculation. After 14 to $18 \mathrm{~d}$, roots of plants with yellow leaves were examined to observe the extent of nodulation. Plants that had no nodules $\left(\mathrm{Nod}^{-}\right)$or white nodules $\left(\mathrm{Fix}^{-}\right)$were retained, potted, and grown to maturity.

\section{Results}

EFFECT OF EMS CONCENTRATION ON PLANT SURVIVAL, DEVELOPMENT, AND YIELD. Initial experiments testing EMS concentrations on the germination of BAT 93 seed indicated that high concentrations of EMS resulted in a dramatic reduction in germination. In experiments using two different protocols (Fig. 2), concentrations in excess of $40 \mathrm{~mm}$ EMS resulted in germination rates of less than $10 \%$, whereas EMS concentrations of $20 \mathrm{~mm}$ or lower gave germination rates of $60 \%$ or more. Pretreatment of the seed with water for $8 \mathrm{~h}$, using the Caldwell et al. (2004) protocol, resulted in a reduction in overall germination rates (Fig. 2B-C). Based on a target germination rate of $10 \%$ or higher, additional EMS treatments were added in the vicinity of the $40 \mathrm{~mm}$ treatment in subsequent experiments and the pretreatment of seed with water was eliminated.

Subsequent experiments tested EMS concentrations of 0 , 20, 30, 40, 50, and $60 \mathrm{~mm}$ and evaluated plant development and seed yield components in addition to germination rates (Table 2). EMS treatment delayed germination as compared with untreated seed. Evaluation of the plants $14 \mathrm{~d}$ after germination was found to more accurately reflect actual germination after EMS treatment. Significant differences in germination at $14 \mathrm{~d}$ were found between no treatment and EMS concentrations of $40 \mathrm{~mm}$ or higher. Although EMS concentrations of $60 \mathrm{~mm}$ resulted in germination rates of less than $10 \%$, $50 \mathrm{~mm}$ EMS still yielded effective germination rates (greater than $10 \%$ ). Plant height at $14 \mathrm{~d}$ was significantly reduced by EMS treatment and there was little variation in plant height at EMS concentrations above $40 \mathrm{~mm}$.

Seed yield components and other indices, including pod number, seed number, and harvest index, showed a similar response to EMS concentration (Table 2). Significant reductions in pod number occurred with $30 \mathrm{~mm}$ EMS or more and in seed yield and harvest index with $20 \mathrm{~mm}$ EMS or more. There were no significant differences in these yield traits between EMS treatments above $30 \mathrm{~mm}$. Aboveground vegetative biomass followed an opposite trend to seed yield from 0 to $30 \mathrm{~mm}$ EMS, which indicates that there was vegetative yield compensation as a result of reduced seed yield. At higher EMS concentrations (40 to $60 \mathrm{~mm}$ ), however, vegetative biomass was increasingly affected by the EMS treatment.

EMS-treated seedlings that survived after germination did not necessarily produce seed. Seedlings that survived EMS concentrations of 50 and $60 \mathrm{~mm}$ showed less than $50 \%$ transplant 
survival (Table 2). Overall survival showed an inverse response with increasing EMS concentration. Large reductions in overall survival occurred with concentrations of $30 \mathrm{~mm}$ or higher EMS. Concentrations of 50 and $60 \mathrm{~mm}$ EMS resulted in overall survival rates of less than $10 \%$.

Mutant population Development. Effective TILling requires near saturation of the haploid complement of the genome in a large mutant population. Mutation frequency and tolerance to mutation load varies significantly from species to species (Table 3) and may be influenced by ploidy (Comai and Henikoff, 2006; Henikoff and Comai, 2003; Stadler, 1932). Based on the average mutation frequency of 2.6 or 2.7 mutations $/ \mathrm{Mb}, \approx 4.6$ to 5.0 million mutations were generated in the L. japonicus or M. truncatula TILLING populations, respectively. With the goal of generating greater than 5 million mutations in common bean and assuming a mutation frequency of 2 to 3 mutations/Mb, like with L. japonicus and $M$. truncatula, a population of 5000 lines would generate between 5.9 and 8.9 million mutations. This number of total mutations falls between that of diploid genomes such as $A$. thaliana, $L$. japonicus, and M. truncatula and the more complex, polyploid cereal genomes (Table 3). The cereal genomes such as barley, maize (Zea mays), and wheat (Triticum aestivum) have a higher content of repetitive DNA, more duplication, and larger, polyploid genomes, thus requiring higher mutation density.

Over 3000 M3 lines derived from treatments using 35, 40, 45, and $50 \mathrm{~mm}$ EMS have been generated in genotype BAT 93. Over 2000 M3 lines have been grown in the field, generating M4 seed. DNA has been extracted and stored for TILLING from over 2000 M2 families. Phenotypic screening of 3000 M2 plants has shown a lower frequency of visible mutants in plants from the $35 \mathrm{~mm}$ treatment compared with those from the 40 - to $50 \mathrm{~mm}$ treatments (Table 4). The most frequent mutations have been in leaflet shape, leaflet number, and seed dormancy, three traits that have proven difficult to fix in the M4 generation and which may have resulted from residual mutagen effects visible in the M2 generation only. More stable mutations have been observed for leaf chlorosis, seedcoat color, semi-dwarfing, and dwarfing and are generally inherited as recessive mutations. Late-maturing and spindly growth mutants have also been observed but at a lower frequency. An additional 384 M2 lines from the same population have been tested for nodulation and 33 nodulation-deficient plants were identified. All the M2s characterized as non-nodulating were found to resemble wildtype plants in the subsequent, M3, generation.

\section{Discussion}

Based on overall survival, plant development, yield of treated seed, and phenotypic mutation rate, $40 \mathrm{~mm}$ EMS is an appropriate concentration for the generation of a mutant population suitable for TILLING in genotype BAT 93. Using this concentration, a maximum number of mutations can be generated with a minimum population size and with relatively high efficiency. Higher concentrations of EMS resulted in overall survival rates of less than $10 \%$, which are considered inadequate for efficient mutagenesis and population development, whereas lower concentrations (less than $35 \mathrm{~mm}$ ) resulted in a reduction in the frequency of phenotypic mutants. Overall survival is a better criterion than germination to evaluate EMS mutagen concentration, because EMS-treated seedlings that survive germination often do not produce seed.

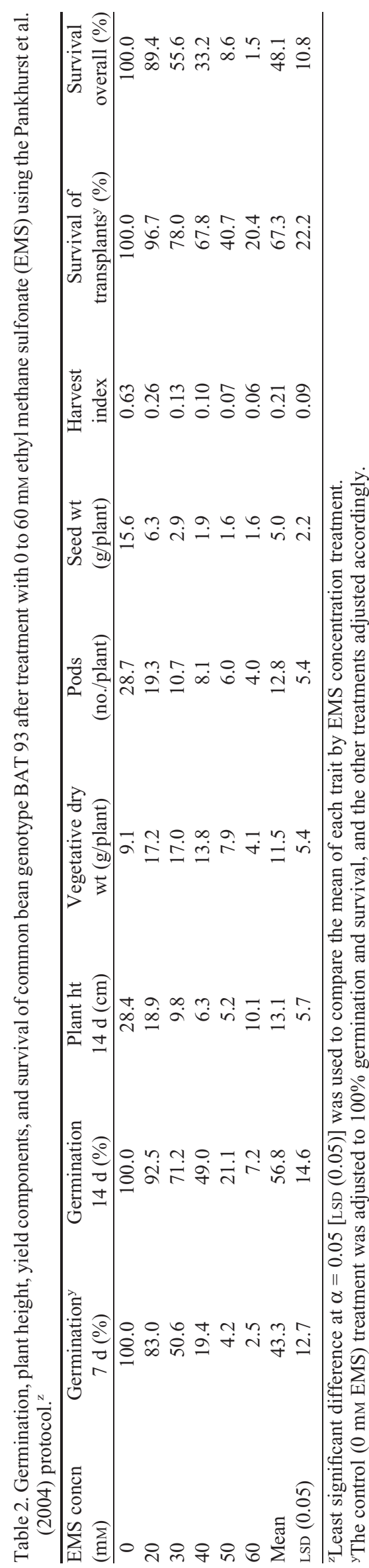




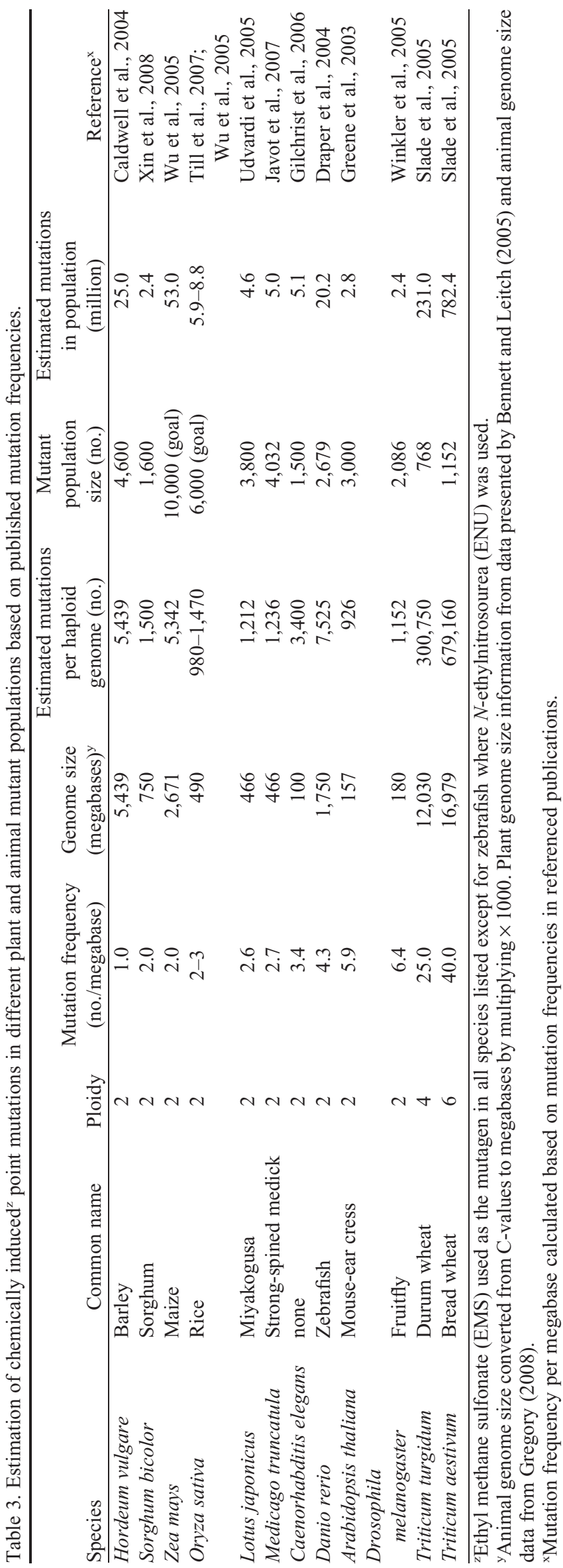

Table 4. Mutation type and observed frequencies in the common bean genotype BAT 93 mutant population of 3000 second generation (M2) plants. ${ }^{z}$

\begin{tabular}{llcc}
\hline & & \multicolumn{2}{c}{ Frequency (\%) } \\
\cline { 3 - 4 } Mutated tissue & \multicolumn{1}{c}{ Mutant type } & EM EMS $^{\mathrm{y}}$ & $\begin{array}{c}40-50 \mathrm{mM} \\
\text { EMS }\end{array}$ \\
\hline Leaf & Chlorotic & 0.00 & 1.53 \\
& Leaflet number & 0.11 & 6.57 \\
Stem & Leaflet shape & 0.11 & 13.41 \\
& Dwarf & 0.00 & 1.97 \\
& Semi-dwarf & 1.15 & 0.92 \\
Seed & Spindly & 0.00 & 1.14 \\
Whole plant & Embryo lethal/dormant & 2.99 & 7.62 \\
Root & Late maturity & 0.00 & 5.04 \\
Other mutations & Nodulation deficiency & \\
& & ND $^{\mathrm{v}}$ & 9.50 \\
& & 0.00 & 0.88
\end{tabular}

${ }^{\mathrm{z}}$ The mutations were generated through seed treatment using ethyl methane sulfonate (EMS).

${ }^{\mathrm{y}}$ Of the $3000 \mathrm{M} 2$ plants, 844 were generated from $35 \mathrm{~mm}$ EMS and 2156 from 40 to $50 \mathrm{~mm}$ EMS treatments.

${ }^{x}$ Dwarf plants were severely reduced in size and often did not produce seed, whereas semidwarf plans were intermediate in stature and generally did produce seed.

wNodulation mutant frequencies based on the $3000 \mathrm{M} 2$ plants and not on the 348 lines mentioned in the text.

${ }^{\mathrm{N}} \mathrm{ND}=$ not determined.

In comparison with mutation frequencies and effective population sizes in other species, a population of 5000 mutant lines is expected to be adequate for genome saturation and effective TILLING of $P$. vulgaris genotype BAT 93. This estimate is based on the predicted mutation frequency of two to three mutations/Mb per haploid complement for such diploid plants as A. thaliana, L. japonicus, and M. truncatula as well as that of the more complex, polyploid cereal genomes. Using concentrations of between 35 and 50 mM EMS, over 3000 M3 lines have been developed that show morphological and phenological mutations at reasonable frequencies. Although mutation frequencies were estimated using phenotypic traits, the actual mutation frequency for BAT 93 will be calculated based on TILLING experiments at specific loci through comparison with natural rates of polymorphism in bean (e.g., Slade et al., 2005; Till et al., 2007). Functional redundancy in specific species such as $A$. thaliana could confer greater tolerance to high mutation load as has been found with yeast (Saccharomyces cerevisia) (Gu et al., 2003). If common bean is similar to other small genome legumes such as $M$. truncatula and L. japonicus with relatively low functional redundancy, it is expected to be less tolerant to high mutation load.

EMS mutagenesis has been shown to be effective in common bean, through isolation of a low phytic acid mutant in another EMS mutant population (Sparvoli et al., 2007). In addition to reverse genetic applications, forward genetic screening of mutants has been used to isolate specific mutants using the BAT 93 mutant population [e.g., for those perturbed in embryogenesis (Silue et al., 2006)]. If identified, beneficial mutations from the population could be directly incorporated into breeding programs using the same molecular tools such as DNA sequence and polymerase chain reaction primers developed as part of the TILLING protocol. Furthermore, because EMS-generated mutant lines are not transgenic, novel lines with agronomically beneficial traits could be incorporated into 
breeding programs without additional hurdles. Once the BAT 93 mutagenesis population developed from this research is completed and the TILLING protocol is optimized for common bean, the population will be used for genetic analysis and will be made available to the research community for the evaluation of specific loci and traits of interest.

\section{Literature Cited}

Allavena, A. 1989. Modification of the seed coat color associated to the I gene conferring resistance to BCMV. Annu. Rpt. Bean Improv. Coop. 32:90-91.

Andersen, A.L. and E.E. Down. 1956. Agronomic use of an x-ray induced mutant. Science 124:223-224.

Arumuganathan, K. and E.D. Earle. 1991. Nuclear DNA content of some important plant species. Plant Mol. Biol. Rpt. 3:208-218.

Bennett, M.D. and I.J. Leitch. 2005. Plant DNA C-values database (release 4.0, Oct. 2005). 24 Mar. 2009. <http://data.kew.org/cvalues/ homepage.html>.

Blair, M.W., C. Galeano, C. Muñoz, M. Bouniol, C. Pankhurst, P. Lariquet, and W.M. Broughton. 2005. Generation of TILLING mutants in common bean. Centro Internacional de Agricultura Tropical (CIAT) Annu. Rpt., Biotechnol. Unit. CIAT, Cali, Colombia.

Broughton, W.J. and M.J. Dilworth. 1971. Control of leghaemoglobin synthesis in snake beans. Biochem. J. 125:1075-1080.

Broughton, W.J., G. Hernandez, M. Blair, S. Beebe, P. Gepts, and J. Vanderleyden. 2003. Beans (Phaseolus spp.)-Model food legumes. Plant Soil 252:55-128.

Caldwell, D.G., N. McCallum, P. Shaw, G.J. Muehlbauer, D.F. Marshall, and R. Waugh. 2004. A structured mutant population for forward and reverse genetics in barley (Hordeum vulgare L.). Plant J. 40:143-150.

Cary, J.W. 1982. Bean mutations from azide: An iron chlorotic strain, but no induced cold hardiness. Annu. Rpt. Bean Improv. Coop. 25:21-22.

Colbert, T., B.J. Till, R. Tompa, S. Reynolds, M.N. Steine, A.T. Yeung, C.M. McCallum, L. Comai, and S. Henikoff. 2001. Highthroughput screening for induced point mutations. Plant Physiol. 126:480-484.

Comai, L. and S. Henikoff. 2006. TILLING: Practical single-nucleotide mutation discovery. Plant J. 45:684-694.

Cooper, J.L., B.J. Till, R.G. Laport, M.C. Darlow, J.M. Kleffner, A. Jamai, T. El-Mellouki, S. Liu, R. Ritchie, N. Nielsen, K.D. Bilyeu, K. Meksem, L. Comai, and S. Henikoff. 2008. TILLING to detect induced mutations in soybean. BMC Plant Biol. 8:9.

Davis, J.H.C., K.E. Giller, J. Kipe-Nolt, and M. Awah. 1988. Nonnodulating mutants in common bean. Crop Sci. 28:859-860.

Draper, B.W., C.M. McCallum, J.L. Stout, A.J. Slade, and C.B. Moens. 2004. A high throughput method for identifying ENU-induced point mutations in zebrafish. Methods Cell Biol. 77:91-112.

Frazier, W.A. and D.W. Davis. 1966a. Inheritance of silver mutant. Annu. Rpt. Bean Improv. Coop. 9:22.

Frazier, W.A. and D.W. Davis. 1966b. Inheritance of dark green savoy mutant. Annu. Rpt. Bean Improv. Coop. 9:22-23.

Freyre, R., P.W. Skroch, V. Geffroy, A.-F. Adam-Blondon, A. Shirmohamadali, W.C. Johnson, V. Llaca, R.O. Nodari, P.A. Pereira, S.-M. Tsai, J. Tohme, M. Dron, J. Nienhuis, C.E. Vallejos, and P. Gepts. 1998. Towards an integrated linkage map of common bean. 4. Development of a core linkage map and alignment of RFLP maps. Theor. Appl. Genet. 97:847-856.

Gautam, A.S., K.C. Sood, and R.K. Mittal. 1998. Mutagenic effectiveness and efficiency of gamma-rays and ethyl methane sulphonate in rajma (Phaseolus vulgaris L.). Legume Res. 21:217-220.

Gepts, P., W.D. Beavis, E.C. Brummer, R.C. Shoemaker, H.T. Stalker, N.F. Weeden, and N.D. Young. 2005. Legumes as a model plant family. Genomics for food and feed report of the cross-legume advances through genomics conference. Plant Physiol. 137:1228-1235.
Gilchrist, E.J., N.J. O’Neil, A.M. Rose, M.C. Zetka, and G.W. Haughn. 2006. TILLING is an effective reverse genetics technique for Caenorhabditis elegans. BMC Genomics 7:262.

Greene, E.A., C.A. Codomo, N.E. Taylor, J.G. Henikoff, B.J. Till, S.H. Reynolds, L.C. Enns, C. Burtner, J.E. Johnson, A.R. Odden, L. Comai, and S. Henikoff. 2003. Spectrum of chemically induced mutations from a large-scale reverse-genetic screen in Arabidopsis. Genetics 164:731-740.

Gregory, T.R. 2008. Animal genome size database. 24 Mar. 2009. $<$ http://www.genomesize.com/search.php $>$.

Gu, Z., L.M. Steinmetz, X. Gu, C. Scharfe, R.W. Davis, and W.H. Li. 2003. Role of duplicate genes in genetic robustness against null mutations. Nature 421:63-66.

Henikoff, S. and L. Comai. 2003. Single-nucleotide mutations for plant functional genomics. Annu. Rev. Plant Biol. 54:375-401.

Hussein, H.A.S. and I.A.M. Disouki. 1976. Mutation breeding experiments in Phaseolus vulgaris (L.) I. EMS and gamma-ray-induced seed coat colour mutants. Zeitschrift für Pflanzenzüchtung 76:190-199.

Javot, H., R.V. Penmetsa, N. Terzaghi, D.R. Cook, and M.J. Harrison. 2007. Phosphate delivery by MtPT4 is indispensable for the arbuscular mycorrhizal symbiosis. Proc. Natl. Acad. Sci. USA 104:1720-1725.

Kami, J., V. Poncet, V. Geffroy, and P. Gepts. 2006. Development of four phylogenetically-arrayed BAC libraries and sequence of the APA locus in Phaseolus vulgaris. Theor. Appl. Genet. 112:987-998.

Kelly, J.D., P. Gepts, P.N. Miklas, and D.P. Coyne. 2003. Tagging and mapping of genes and QTL and molecular marker-assisted selection for traits of economic importance in bean and cowpea. Field Crops Res. 82:135-154.

McCallum, C.M., L. Comai, E.A. Greene, and S. Henikoff. 2000. Targeting induced local lesions in genomes (TILLING) for plant functional genomics. Plant Physiol. 123:439-442.

Melotto, M., C.B. Monteiro-Vitorello, A.G. Bruschi, and L.E. Camargo. 2005. Comparative bioinformatic analysis of genes expressed in common bean (Phaseolus vulgaris L.) seedlings. Genome 48:562-570.

Moh, C.C. 1971. Mutation breeding in seed-coat colors of bean (Phaseolus vulgaris L.). Euphytica 20:119-125.

Mohan, D.P., P.S. Benepal, A.Q. Sheikh, and M. Rangappa. 1980. Determination of optimal mutagenic dose of ethylmethane sulfonate, diethyl sulfate and ethidium bromide for beans (Phaseolus vulgaris L.). Annu. Rpt. Bean Improv. Coop. 23:115-117.

Motto, M., G.P. Soressi, and F. Salamini. 1975. Growth analysis in a reduced leaf mutant of common bean (Phaseolus vulgaris L.). Euphytica 28:593-600.

Nagata, R.T. and M.J. Bassett. 1984. Characterization and inheritance of gamma ray induced mutations in common bean. J. Amer. Soc. Hort. Sci. 109:513-516.

Pankhurst, C.E., M.W. Blair, and W.J. Broughton. 2004. TILLING the beans. Proc. Phaseomics III Conf., University of Geneva, 13-25 June 2004 (abstr.).

Park, S.J. and B.R. Buttery. 1989. Inheritance of nitrate-tolerant supernodulation in EMS induced mutants of common bean (Phaseolus vulgaris L.). J. Hered. 80:486-488.

Perry, J.A., T.L. Wang, T.J. Welham, S. Gardner, J.M. Pike, S. Yoshida, and M. Parniske. 2003. A TILLING reverse genetics tool and a web-accessible collection of mutants of the legume Lotus japonicus. Plant Physiol. 131:866-871.

Pueppke, S.G. and W.J. Broughton. 1999. Rhizobium sp. NGR234 and $R$. fredii USDA257 share exceptionally broad, nested host-ranges. Mol. Plant Microbe Interact. 12:293-318.

Ramírez, M., M.A. Graham, L. Blanco-López, S. Silvente, M.W. Blair, G. Hernández, C.P. Vance, and M. Lara. 2005. Sequencing and analysis of common bean ESTs. Building a foundation for functional genomics. Plant Physiol. 137:1211-1227.

Sanchez-Valdez, I., J.A. Acosta-Gallegos, F.J. Ibarra-Perez, R. Rosales-Serna, and S.P. Singh. 2004. Registration of 'Pinto Saltillo' common bean. Crop Sci. 44:1865-1866. 
Sarafi, R. 1973. Utilisation de rayons ionisants dans l'amelioration du haricot (Phaseolus vulgaris L.). Annales de l' amelioration des plantes 23:77-81.

Silue, S., P. Lariguet, C. Pankhurst, J.M. Jacquemin, W.J. Broughton, and J.P. Baudoin. 2006. Screening Phaseolus vulgaris L. EMS mutants to isolate plants failing in seed development and to study genetics of embryogenesis. Annu. Rpt. Bean Improv. Coop. 49:149-150.

Slade, A.J., S.I. Fuerstenberg, D. Loeffler, M.N. Steine, and D. Facciotti. 2005. A reverse genetic, nontransgenic approach to wheat crop improvement by TILLING. Nat. Biotechnol. 23:75-81.

Sparvoli, F., E. Nielson, B. Campion, E. Doria, T. Galasso, M. Fileppi, G. Tagliabue, M.G. Daminati, S. Rasmussen, and R. Bollini. 2007. Identification and characterization of low phytic acid (lpa) mutant in bean. Proc. Phaseomics V Conf., Varenna, Italy, 23-26 May:13 (abstr.). Stadler, L.J. 1932. On the genetic nature of induced mutations in plants. Proc. 6th Congr. Genet. 1:274-294.

Svetleva, D. 2004. EMS and NEU mutagenic efficiency and effectiveness in induction of morphological mutations in Phaseolus vulgaris L. II. Annu. Rpt. Bean Improv. Coop. 47:177-178.

Till, B.J., J. Cooper, T.H. Tai, P. Colowit, E.A. Greene, S. Henikoff, and L. Comai. 2007. Discovery of chemically induced mutations in rice by TILLING. BMC Plant Biol. 7:19.

Tulmann-Neto, A. and A. Ando. 1976. Induced mutation in beans (Phaseolus vulgaris) to obtain varieties resistant to golden mosaic virus. Annu. Rpt. Bean Improv. Coop. 19:86.

Udvardi, M.K., S. Tabata, M. Parniske, and J. Stougaard. 2005. Lotus japonicus: Legume research in the fast lane. Trends Plant Sci. 10:222-228.
Vanhouten, W. and S. MacKenzie. 1999. Construction and characterization of a common bean bacterial artificial chromosome library. Plant Mol. Biol. 40:977-983.

Voysest, O. 1983. Variedades de frijol en América Latina y su origen. Centro Internacional de Agricultura Tropical (CIAT), Cali, Colombia. Voysest, O. 2000. Mejoramiento genético del frijol (Phaseolus vulgaris L.). Legado de variedades de América Latina 1930-1999. Centro Internacional de Agricultura Tropical (CIAT), Cali, Colombia.

Winkler, S., A. Schwabedissen, D. Backasch, C. Bokel, C. Seidel, S. Bonisch, M. Furthauer, A. Kuhrs, L. Cobreros, and M. Brand. 2005. Target-selected mutant screen by TILLING in Drosophila. Genome Res. 15:718-723.

Wu, J.L., C. Wu, C. Lei, M. Baraoidan, A. Bordeos, M.R. Madamba, M. Ramos-Pamplona, R. Mauleon, A. Portugal, and V.J. Ulat. 2005. Chemical- and irradiation-induced mutants of indica rice IR64 for forward and reverse genetics. Plant Mol. Biol. 59:85-97.

Wyatt, J.E. and P.D. Dukes. 1980. A seed coat color mutation in beans induced by gamma radiation. Annu. Rpt. Bean Improv. Coop. 23:34.

Xin, Z., M.L. Wang, N.A. Barkley, G. Burow, C. Franks, G. Pederson, and J. Burke. 2008. Applying genotyping (TILLING) and phenotyping analyses to elucidate gene function in a chemically induced sorghum mutant population. BMC Plant Biol. 8: 103.

Zogorcheva, L. and I. Poriazov. 1983. Induction of mutation in green beans by gamma rays. Annu. Rpt. Bean Improv. Coop. 26: 89-90. 